ground. ${ }^{2}$ Damage to the mitral valve may occur when the heart is violently compressed at the end of diastole, when the left ventricle is full. ${ }^{3}$ This may cause rupture of the chordae tendineae or papillary muscles or damage to the valve leaflets themselves. In severe cases symptoms may occur directly after the injury, but in some cases they may be delayed for several years. ${ }^{5}$

Our patient's posterior mitral valve prolapse was probably due to damage to the chordae tendineae sustained during the crush at the football ground. Such cases have medicolegal implications as mitral valve surgery may become necessary.

E D GRECH C M BELLAMY

E J EPSTEIN

Cardiothoracic Centre,

Liverpool NHS Trust,

Liverpool L14 3PE

1 Wardrope J, Ryan F, Clark G, Venables G, Courtney Crosby A, Redgrave P. The Hillsborough tragedy. BMF 1991;303: 1381-5. (30 November.)

2 Channer KS, Edbrooke DL, Moores M, McHugh P, Michael S. Acute right heart strain after crushing injury at Hillsborough football ground. $B M \mathcal{F}$ 1989;299:1379-80.

3 Parmley LF, Manion WC, Mattingly TW. Nonpenetrating traumatic injury of the heart. Circulation 1958;18:371-96.

4 McLaughlin JS, Cowley RA, Smith G, Maheson NA. Mitra valve disease from blunt trauma. $\mathcal{F}$ Thorac Cardiovasc Surg 1964;48:261-71.

5 Symbas P. Cardiac trauma. Am Heart f 1976;92:387-96

SIR, - I must correct an error in James Wardrope and colleagues' article on the Hillsborough tragedy, which claimed that the South Yorkshire Metropolitan Ambulance and Paramedic Service gave no notification to the Northern General Hospital that a major incident was taking place. ${ }^{1}$ The hospital was notified of a major incident at about 1525 hours, before any casualties arrived. That information was given, in person, by an ambulanceman to a member of the hospital staff, who appeared to act on it. Any suggestion that the hospital had not received notification is therefore incorrect.

With regard to the part of the discussion headed "implications for disaster planning," this service made formal representations at Lord Justice Taylor's inquiry and was instrumental in introducing legislation to increase the emergency provision in football stadiums.

A PAGE

South Yorkshire Metropolitan Ambulance and

Paramedic Service,
Rotherham S60 2BQ

1 Wardrope J, Ryan F, Clark G, Venables G, Courtney Crosby A Redgrave P. The Hillsborough tragedy. BMf 1991;303: 1381-5. (30 November.)

\section{Low blood pressure, low mood?}

SIR,-John A Pilgrim and colleagues' paper looking at the relation between low blood pressure and low mood ' and Anthony Mann's accompanying editorial $^{2}$ prompted me to examine data from a study investigating the relations of aspects of pregnancy with psychological and psychosocial factors. The study is of women expecting their second child and includes completion of a hospital anxiety and depression scale $^{3}$ at 20-22 weeks' gestation. This scale correlates well with the general health questionnaire used in the Whitehall II study. ${ }^{+}$Measurements of blood pressure taken around this time are available from hospital case notes. I defined low blood pressure as the lowest quartile of both systolic and diastolic blood pressures (systolic $<110 \mathrm{~mm} \mathrm{Hg}$ and diastolic $<65 \mathrm{~mm} \mathrm{Hg}$ ) and low mood as a score of $>7$ on either subscale of the hospital anxiety and depression scale.

Although a higher proportion of women with low blood pressure experienced low mood, the association was not significant $\left(\chi^{2}=0 \cdot 87, \mathrm{df}=1\right)$ There were, however, apparent associations of low blood pressure and low mood with low birth weight and preterm birth (table). The odds ratios for the cells for low blood pressure and low mood in the table were 4.76 (95\% confidence interval 1.36 to 16.72$)$ for low birth weight and $5.33(1.71$ to 16.69) for preterm birth.

These associations may be multiply confounded -for example, by smoking-and analysis of these data is continuing. Nevertheless, these observations in a relatively young sample of pregnant women (average age $25 \cdot 6$ (SD 3.2) years) provide a further argument for better understanding of the relation between low blood pressure and low mood.

COLIN PRITCHARD

Public Health Research Unit, Glasgow G12 8RZ

1 Pilgrim JA, Stansfield S, Marmot M. Low blood pressure, low mood? BMF 1992;304:75-8. (11 January.)

2 Mann A. Psychiatric symptoms and low blood pressure. $B M \mp$ 1992;304:64-5. (11 January.)

Zigmond AS, Snaith RP. The hospital anxiety and depression scale. Acta Psychiatr Scand 1983;67:361-70.

4 Wilkinson MJB, Barczak P. Psychiatric screening in genera practice: comparison of the general health questionnaire and the hospital anxiety and depression scale. $\mathscr{O} R$ Coll Gen Pract 1988;38:311-3.

\section{Unexpected problems with patient controlled analgesia}

SIR,-Patient controlled analgesia has become a routine part of the management of postoperative pain. After new equipment was introduced into this hospital we audited the patient controlled analgesia service. Twenty one patients receiving patient controlled analgesia after elective surgery were visited in the recovery room and daily in the ward until the analgesia was stopped. Although most of the patients were satisfied with their analgesia, several unexpected problems were found.

A 58 year old woman, who initially used her analgesia pump without any problems, was later found to be comatose, unresponsive to sternal pressure, and with fixed, dilated pupils and a respiratory rate of 8 breaths/minute. After treatment with naloxone she recovered. She later explained that she had believed the demand button for patient controlled analgesia to be the nurse cal device and had been pressing it repeatedly. Patien controlled analgesia was stopped, and she recovered uneventfully.

Proportions of women giving birth to low birthweight babies and preterm babies by blood pressure and mood

\begin{tabular}{|c|c|c|c|c|c|c|}
\hline & \multicolumn{2}{|c|}{ Low mood } & \multicolumn{2}{|c|}{ Not low mood } & \multicolumn{2}{|c|}{ All patients } \\
\hline . & $\begin{array}{c}\text { No (\%) with } \\
\text { low birth weight }\end{array}$ & $\begin{array}{l}\text { No(\%) with } \\
\text { preterm birth }\end{array}$ & $\begin{array}{c}\text { No (\%) with } \\
\text { low birth weight }\end{array}$ & $\begin{array}{c}\text { No (\%) with } \\
\text { preterm birth* }\end{array}$ & $\begin{array}{c}\text { No }(\%) \text { with } \\
\text { low birth weight }\end{array}$ & $\begin{array}{c}\text { No(\%) with } \\
\text { preterm birth }\end{array}$ \\
\hline Low blood pressure & $3 / 26(11 \cdot 5)$ & $4 / 25(16 \cdot 0)$ & $0 / 28(0 \cdot 0)$ & $0 / 28(0 \cdot 0)$ & $3 / 54(5 \cdot 6)$ & $4 / 53(7 \cdot 6)$ \\
\hline Not low blood pressure & $6 / 151(4 \cdot 0)$ & $7 / 150(4 \cdot 7)$ & $6 / 232(2 \cdot 6)$ & $8 / 231(3.5)$ & $12 / 383(3 \cdot 1)$ & $15 / 381(3.9)$ \\
\hline All patients & $9 / 177(5 \cdot 1)$ & $11 / 175(6 \cdot 3)$ & $6 / 260(2 \cdot 3)$ & $8 / 259(3 \cdot 1)$ & $15 / 437(3.4)$ & $19 / 434(4 \cdot 4)$ \\
\hline
\end{tabular}

*Gestational age was not ascertained in three cases.
After the syringe is changed the settings on the analgesia pumps (Lifecare, Abbott Laboratories) need to be confirmed. In three cases the four hour limit was incorrectly set at $1 \mathrm{mg}$ (twice by a house officer, once by junior nursing staff). Patients therefore received inadequate analgesia despite repeatedly pressing the demand button.

During the postoperative period patients are moved about, and on these occasions the machine is unplugged from the mains. In three cases the mains supply was not reconnected and the back up battery supply was later found to be almost exhausted.

These problems indicate the need for careful monitoring and supervision of patients receiving patient controlled analgesia. Measures have now been taken to improve staff's and patients' understanding of patient controlled analgesia and its equipment. Clearly, the introduction of a patient controlled analgesia service demands more than simply buying the equipment.

MIRANDA FARMER N J N HARPER

Department of Anaesthesia,

Manchester Royal Infirmary,

Manchester M13 9WL

\section{Ocular injuries from boxing}

SIR,-In his editorial on ocular injuries from boxing David McLeod mentions that the Boxing Board of Control has visual standards below which no one is allowed to hold a professional licence. ${ }^{1}$ Another part of the same regulation excludes any boxer who has suffered any intraocular pathology, including a retinal hole, tear, or detachment. This exclusion has been vigorously opposed by, among others, McLeod, who has stated that a repaired retina is stronger than even a normal retina and someone with a repaired retina is not predisposed to any other intraocular injury, such as has occurred with a professional boxer who has recently been treated. I can find no papers to confirm McLeod's assertions and would be interested to hear of any.

McLeod asks whether the boxing board has the courage and clout to stage a longitudinal study of the effectiveness of any preventive measures. As the board's chief medical officer I would be pleased to cooperate in any study aimed at preventing eye injuries in the ring and at establishing the correct procedure for dealing with the results of eye damage provided that funds-which, sadly, the Boxing Board of Control does not have-were made available.

Chief Medical Officer,

British Boxing Board of Control,

London W1M 7DE

1 McLeod D. Ocular injuries from boxing. BMf 1992;304:197. (25 January.)

\section{Diagnosing Alzheimer's disease}

SIR, - Minerva ${ }^{1}$ reports the findings of Burns et $a$ that around a fifth of patients with Alzheimer's disease are misclassified by computed tomography. ${ }^{2}$ In their paper Burns et al wrote, "Although single photon emission tomography and magnetic resonance imaging can give more detailed information about cerebral function and structure, these are more arduous for the patient and [computed tomography] remains the most applicable in the clinical practice of old age psychiatry." They state this even though 40 of 178 patients with Alzheimer's disease were unable for various reasons to have computed tomography.

We have just completed a pilot study looking at the ability of magnetic resonance imaging and single photon emission tomography to differentiate 